OPEN ACCESS

Edited by:

Mohammad Badruzzaman Khan, Augusta University, United States

Reviewed by:

Amjad Khan,

Gyeongsang National University,

South Korea

Mohammad Farhan

Hamad bin Khalifa University, Qatar

Samath Madhyastha,

Kuwait University, Kuwait

*Correspondence:

Ferdinando Franzoni

ferdinando.franzoni@unipi.it

${ }^{t}$ These authors have contributed equally to this work

Specialty section:

This article was submitted to Neurodegeneration,

a section of the journal

Frontiers in Neuroscience

Received: 23 June 2021

Accepted: 09 September 2021

Published: 13 October 2021

Citation:

Franzoni F, Scarfò G, Guidotti S,

Fusi J, Asomov M and Pruneti C (2021) Oxidative Stress and Cognitive Decline: The Neuroprotective Role of

Natural Antioxidants.

Front. Neurosci. 15:729757.

doi: 10.3389/fnins.2021.729757

\section{Oxidative Stress and Cognitive Decline: The Neuroprotective Role of Natural Antioxidants}

\author{
Ferdinando Franzoni ${ }^{\text {*t }}$, Giorgia Scarfò ${ }^{1+}$, Sara Guidotti ${ }^{2}$, Jonathan Fusi ${ }^{1}$, \\ Muzaffar Asomov ${ }^{1}$ and Carlo Pruneti ${ }^{2}$
}

${ }^{1}$ Department of Clinical and Experimental Medicine, University of Pisa, Pisa, Italy, ${ }^{2}$ Department of Medicine and Surgery,

University of Parma, Parma, Italy

Free- radicals (Oxygen and Nitrogen species) are formed in mitochondria during the oxidative phosphorylation. Their high reactivity, due to not-engaged electrons, leads to an increase of the oxidative stress. This condition affects above all the brain, that usually needs a large oxygen amount and in which there is the major possibility to accumulate "Reacting Species." Antioxidant molecules are fundamental in limiting freeradical damage, in particular in the central nervous system: the oxidative stress, in fact, seems to worsen the course of neurodegenerative diseases. The aim of this review is to sum up natural antioxidant molecules with the greatest neuroprotective properties against free radical genesis, understanding their relationship with the Central Nervous System.

Keywords: oxidative stress, cognitive decline, natural antioxidants, neurodegenerative diseases, neuroprotection

\section{INTRODUCTION}

Oxidative stress is known to be involved in the pathogenesis of several diseases: in particular, a strict connection between a free-radical increase and the onset of neurodegenerative disorders has been widely demonstrated (Migliore and Coppedè, 2009).

Free radicals are atoms or molecules characterized by one or more electrons not engaged in chemical bonds, which, remaining unpaired, tend to accept electrons from other molecules: this reaction causes their oxidation (Harman, 1956; Valko et al., 2007). An oxidation-reduction imbalance in living organisms leads to an excess of reactive oxygen and nitrogen species (RONS) with a consequent oxidative stress status (Valko et al., 2007; Sies, 2015) that is classified as basal, low, intermediate, and high according to its intensity (Kishida and Klann, 2007; Lushchak, 2014).

There is a large number of antioxidant defensive mechanisms against RONS. The antioxidant molecules are divided into two groups: enzymatic and non-enzymatic compounds. The enzymatic group includes superoxide dismutase (SOD), catalase (CAT), glutathione peroxidase (GPx) and glutathione reductase (GR). SOD, one of the main protective mechanisms against ROS, catalyzes the conversion of O2- to $\mathrm{H}_{2} \mathrm{O}_{2}$ and $\mathrm{O}_{2}$ (Halliwell and Gutteridge, 1984), while CAT converts the generated $\mathrm{H}_{2} \mathrm{O}_{2}$ into water and $\mathrm{O}_{2}$ (Rodriguez-Rocha et al., 2013). The non-enzymatic group involves glutathione (GSH), abundant in brain cells, thioredoxin (Trx), vitamins $\mathrm{A}, \mathrm{E}$ and $\mathrm{C}$, selenium, retinoic acid, carotenoids, and flavonoids. GSH reacts with ROS to generate glutathione disulfide (GSSG) and enters a cycle together with GPx and GR (Cenini et al., 2019).

All these systems are essential to protect us against a possible free radical damage. Since the brain consumes a large amount of oxygen (about $20 \%$ more than other parts of the body), if antioxidant 
defenses are insufficient and levels of polyunsaturated lipids are high, there will be the possibility of an accumulation of biomolecules damaged by RONS (Wang et al., 2012). So, neuronal cells are particularly vulnerable to oxidative damage because of their high oxygen consumption, the weak antioxidant defense (Cobley et al., 2018) and high content of polyunsaturated fatty acids in their membranes: in fact, the lipids of the neuronal membrane are rich in chains side polyunsaturated fatty acids (PUFA). PUFAs composed of eicosapentaenoic (C20:5) and decosahexanoic (C22:6) acids are particularly vulnerable to free radicals attack due to the double bonds that allow RONS to remove hydrogen ions (Hawkins et al., 1998).

In particular, RONS overproduction in brain cells reacts with cell membrane PUFAs causing their peroxidation (Rahman, 2007). More specifically, lipid peroxidation generates a heterogeneous group of relatively stable products such as malondialdehyde (MDA), 4-hydroxy-2-nonenal (HNE), acrolein and isoprostane (Reed, 2011).

As a result, membrane fluidity decreases causing a greater permeability. This facilitates a massive entry of substances into the intracellular system (e.g., $\mathrm{K}+, \mathrm{Ca} 2+$, etc.), that could alter membrane proteins, enzymes and receptors (Fukuzawa and Gebicki, 1983).

Carbohydrates are also influenced by RONS with the formation of advanced glycation products (AGE) (Gabbita et al., 1998) involved in the development of neurodegenerative disorders (Ahmed, 2005).

In addition, RONS alter DNA and RNA heterocyclic bases, in particular guanine: these alterations occur in Parkinson's disease (PD) affected brains. Instead, Alzheimer's Disease (AD) affected brains, are characterized by elevated carbonylation and nitration, that respectively, introduce in proteins carbon monoxide or one or more $\mathrm{NO}_{2}$ groups derived from nitric acid (Alam et al., 1997; Ahmed, 2005).

All neurodegenerative disorders share several common characteristics, such as an abnormally aggregated protein accumulation and mitochondrial dysfunction that demonstrate an oxidative stress status (Abramov et al., 2017). In particular, neurodegeneration-involved reactive species are hydrogen peroxide $\left(\mathrm{H}_{2} \mathrm{O}_{2}\right)$, superoxide anion $\left(\mathrm{O}_{2}{ }^{-}\right)$and highly reactive hydroxyl radical ( $\mathrm{HO} \cdot$ ) (Cooke et al., 2003). They are able to preclude the protein reduction, cause translation errors in vivo altering protein structure, and function (Dukan et al., 2000).

In addition, Nitric Oxide (NO) appears to play an important role in neurological disorders. It has one unpaired electron that makes it highly susceptible to other molecules. Released into the bloodstream, it is oxidized to form nitrite and nitrate (Lundberg et al., 2008; Tewari et al., 2021). The synthesis of NO is regulated by Nitric Oxide Synthase (NOS) that, in the human body exists in three forms: inducible nitric oxide synthase (iNOS), neuronal nitric oxide synthase (nNOS) and the endothelial nitric oxide synthase (eNOS). The amount of NO, produced by these different isoforms, shows a different physiological activity. At low concentrations, NO seems to have a neuroprotective effect: studies in animals model showed that NOS inhibition correlated with the genesis and the progression of $\mathrm{PD}$, and with a decreased neuronal apoptosis (Steinert et al., 2010). Nevertheless, NO at high concentrations, induces a proinflammatory stimulus with a neurotoxic effect (Good et al., 1998; Tse, 2017): a study conducted on PD affected brains, demonstrated that NO and peroxynitrite were involved in the degeneration of neurons in the substantia nigra pars compacta (Moncada and Higgs, 1993).

The risk of developing neurodegenerative disorders is also related to some lifestyle factors, such as obesity, sedentary lifestyle, and unbalanced diet, because of their role in RONS genesis (Tan et al., 2018; Nuzzo et al., 2019).

Therefore, considering the fact that oxidative stress is one of the most important risk factors involved in the onset, maintenance and progression of neurodegenerative diseases, a healthy and balanced diet, with its consequent intake of natural antioxidants, could have a fundamental protective role against them (Steele, 2007; Johri and Beal, 2012; Kumar and Ratana, 2016; Khan et al., 2018).

The oxidative stress theory and its consequences at cellular level is shown in Figure 1.

\section{VITAMIN C AND E}

A diet characterized by vegetables and fruits, usually rich in Vitamin C, carotenoids, and Vitamin E, is positively associated with cognitive efficiency and reduced the risk of dementia in the elderly.

From a chemical point of view, Vitamin $\mathrm{C}$ is defined as Ascorbic Acid (AA). It has six-carbon compound that contain two acid-ionizing groups (Ballaz and Rebec, 2019). In the human body, the brain is the region with the highest concentration of AA (Smythies, 1996). This high concentration, attests to the fundamental involvement of AA in the brain function. Indeed, many studies suggest that AA has a neuroprotective role thanks to an antioxidant activity modulation (Harrison et al., 2010a,b). This modulation is related to the buffering of the oxidizing species induced by methamphetamine (Ito et al., 2007), homocysteine (Machado et al., 2011), ethanol (Tian et al., 2016) and other molecules (Gudelsky, 1996; Stansley and Yamamoto, 2014).

It is interesting to note that the AA activity is quite vast, also considering the interaction with Vitamin E. Their association is remarkable in the protection of membranes and other hydrophobic compartments (Beyer, 1994; Getoff, 2013).

A clinical study has highlighted the association between vitamin $\mathrm{E}$ and $\mathrm{C}$ intake and a delayed $\mathrm{AD}$ onset in a group of elderly subjects (Shen and Ji, 2012); similar results were also obtained by Shen and colleagues in 2012 (Kontush and Shekatolina, 2004). In fact, it has been shown that a supplementation of these vitamins and so their greater concentration in cerebrospinal fluids can prevent lipid oxidation in AD patients (Taghizadeh et al., 2017).

The importance of vitamin $\mathrm{C}$ in preventing and combating neurological disorders has also been demonstrated in a recent work: in a murine model, decreased levels of AA levels influenced the neural network development, and this alteration correlated with the pathophysiology of neurological disorders (Ikeda et al., 2021). 


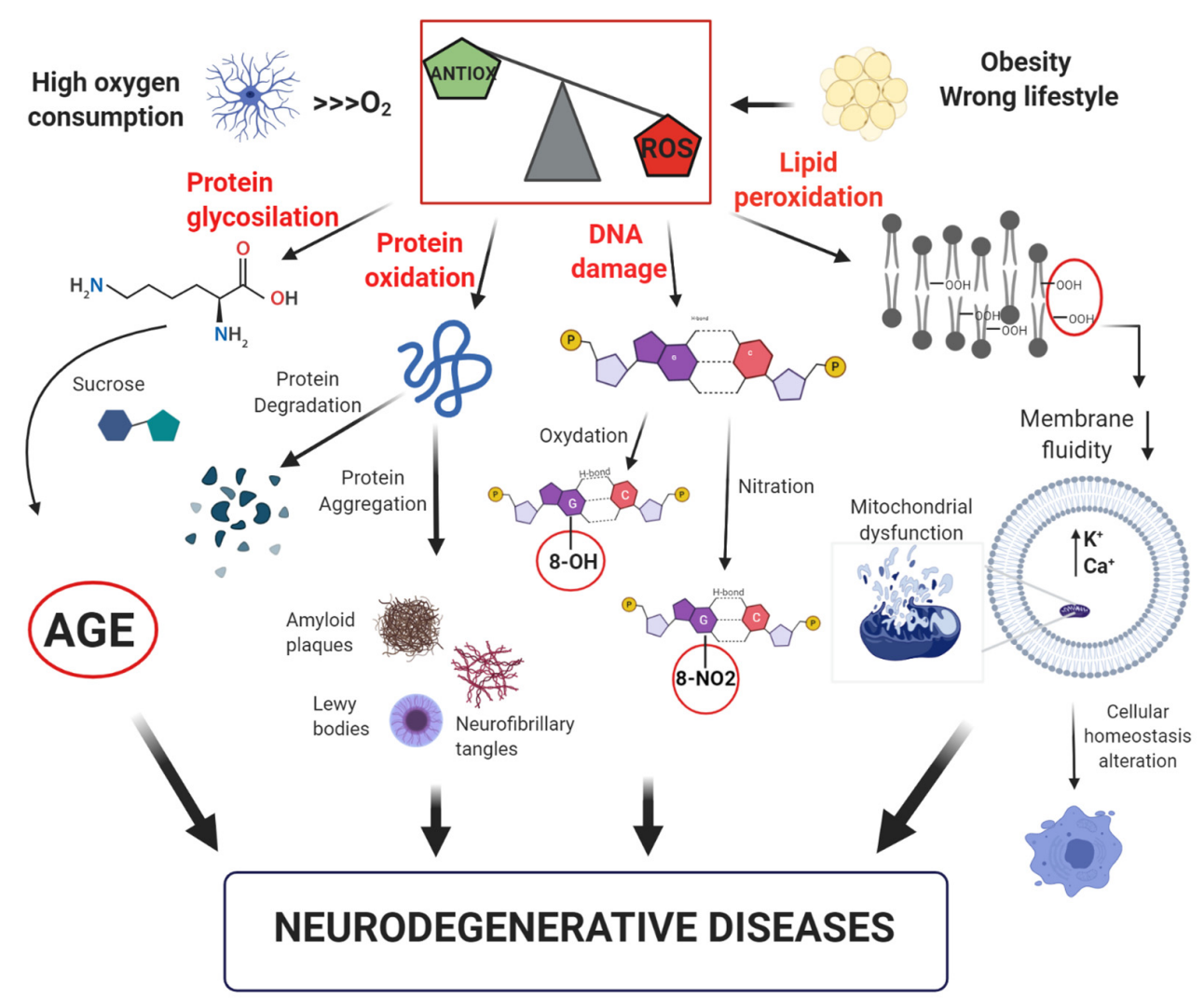

FIGURE 1 | Model of free-radical formation and its consequences at a cellular level. The intense oxygen consumption in the brain induces the formation of reactive oxygen species (ROS). Their high reactivity leads to an increase of the oxidative stress, which promotes: (i) glycosylation and oxidation of proteins, leading to the formation of advanced glycation products (AGE) or loss of protein function; (ii) DNA damage with oxidation or nitration of guanine bases; (iii) lipid peroxidation with reduction of membrane fluidity and increase in cell permeability, resulting in alteration of cellular homeostasis. All these factors can contribute to the development of neurodegenerative disorders.

In an in vitro study, Lee et al. (2021) investigated the protective effect of AA administration in preventing age-induced oxidative damage in hippocampal neurons, demonstrating that a regular AA treatment protected hippocampal neurons from free radical damages.

Vitamin E is a lipophilic molecule that could be found in plants and in many Mediterranean diet food (Schirinzi et al., 2019). Vit. E is referred to compounds called tocopherols and tocotrienols (Ulatowski and Manor, 2015). These usually include eight molecules $\left(\alpha-, \beta-, \gamma-, \delta\right.$-tocopherols and $\alpha-, \beta-, \gamma_{-}, \delta-$ tocotrienols), with great antioxidant capacity (Jiang, 2014).

The presence of an electrophilic hydroxyl group on the chroman ring, allows Vitamin $\mathrm{E}$ to be a strong antioxidant. To understand Vitamin $\mathrm{E}$ role as a protective factor in neurodegenerative disorders, it must be considered what happens if it is deficient. For example, it is demonstrated that Vitamin E deficit is related to an impairment of cerebellar Purkinje neurons that are the main integrators of cerebellar neural circuits (Ulatowski and Manor, 2015). As far as PD, evidence suggests that a Vitamin E supplementation can improve symptoms, functional capabilities and the inflammatory state of affected patients (Simonetto et al., 2019).
In addition, Khanna et al. (2003) showed a fundamental role of Vitamin E against glutamate- induced neurotoxicity. In a later study, it is observed that the co-treatment with vitamin $\mathrm{E}$ analogs can block $\mathrm{NO}$ or $\mathrm{O} 2$. donor-induced cell death in rat striatal cultures (Osakada et al., 2004).

Therefore, the use of vitamins $\mathrm{E}$ and $\mathrm{C}$ as antioxidant supplements is fundamental to delay the onset of neurodegenerative disorders and their complications.

\section{FATTY ACIDS}

Recently, it has grown an interest in polyunsaturated fatty acids (PUFAs) and their beneficial effects on health, due to their strong antioxidant properties (Fotuhi et al., 2009; Sokoła-Wysoczańska et al., 2018). PUFAs (omega-3 and omega- 6 fatty acids) usually have two or more double bonds in the carbon chain structure. Omega- 6 fatty acids include linoleic acid (LA), $\gamma$-linolenic acid (GLA) and arachidonic acid (AA). Omega-3 fatty acids include eicosapentaenoic acid (EPA) and docosahexaenoic acid (DHA).

Their intake is important since their limited synthesis in humans (Youdim et al., 2000; Fotuhi et al., 2009; Sokoła-Wysoczańska et al., 2018). 
Cell-membrane PUFAs composition could be modified with dietary supplementation but it depends on age and probably also on the quantity PUFAs integration (Calder, 2006). High fatty acid diet increases their percentage in inflammatory cell membranes of inflammatory cell and reduces AA levels, a stress-related biomarker and an inflammatory process trigger (through pro-inflammatory eicosanoids production) (Calder, 2002; Dyall, 2015).

Polyunsaturated fatty acids, in particular EPA and DHA, are interesting because of their beneficial effects in preventing cognitive decline through neuroprotective properties such as increasing nerve membrane neuroplasticity, promoting synaptogenesis, modulating signal transduction pathways in neuronal cells, and attenuating inflammatory processes (Youdim et al., 2000; Miller et al., 2017; Sokoła-Wysoczańska et al., 2018).

Furthermore, DHA, produced by the desaturation and elongation of $\alpha$-linolenic acid (ALA), is able to influence a certain number of membrane proteins, such as receptors, ion channels and enzymes. Furthermore, DHA can modulate dopaminergic, serotonergic, and cholinergic neurotransmission, thus regulating signal transduction pathways (Parletta et al., 2013). DHA is also considered important for neurogenesis regulation, neural synapses increase and neuronal damage protection (Cruz-Jentoft et al., 2019).

In fact, Omega-3 DHA is directly absorbed into cell membranes: it composes at least $30 \%$ of the brain matter (in general, fats are more than $50 \%$ of the brain) (Parletta et al., 2013). DHA level decreases significantly both in the blood plasma and in the brain, in physiological aging, above all in $\mathrm{AD}$ patients (Dupont et al., 2019) because of its lower exogenous intake and its greater oxidation (Yurko-Mauro et al., 2015). However, several studies suggest that Omega-3 fatty acid integration is beneficial only in the early stages of cognitive decline (Parletta et al., 2013).

Indeed, there are discrepancies about fatty acid effectiveness on cognitive functioning (Jiao et al., 2014; Burckhardt et al., 2016; Zhang et al., 2016; Stavrinou et al., 2020). That because of multiple variables such as PUFA amount to administer (both omega-3 and omega-6), the type and quality of their source (such as fish oil and/or vegetable oil or other), differences among tests to investigate cognitive efficiency, sample homogeneity in terms of age and functioning and/or cognitive impairment (Stavrinou et al., 2020). A recent double-blind randomized study investigated the effectiveness of fatty acid intake (omega- 3 and omega-6) combined with other antioxidant vitamins in a group of older people with MCI. Neuroaspis PLP10 ${ }^{\circledR}$, a nutraceutical containing omega-3 [EPA (810 mg) / DHA (4,140 mg)], omega6 [GLA (1,800 mg) / LA (3,150 mg)] (1: $1 \mathrm{w} / \mathrm{w})$, vitamin A $(0.6 \mathrm{mg})$ and vitamin $\mathrm{E}(22 \mathrm{mg}$ as $\alpha$-tocopherol plus $760 \mathrm{mg}$ as pure $\gamma$-tocopherol) was administered to the experimental group subjects for 6 months (Beaudart et al., 2019).

In this study (Beaudart et al., 2019), both tests investigating overall cognitive function (ACE-R and MMSE) showed a significant improvement in the experimental group compared to the control group, regarding memory, language (fluency) and visual-spatial skills (ACE-R). An attentional functionality improvement was evidenced too (specifically, in a symbol cancelation test and in the Stroop test, in particular in the word and color subtests but not in the test in which the interference inhibition capacity is investigated). Besides, from a functional point of view, the experimental group obtained high scores in tests investigating muscle strength, endurance, power, and balance. These physical performance parameters are important since they refer to the most demanding daily activities. In parallel, an increase in the quality of life, sleep and perceived fatigue was demonstrated.

The results of this study are similar to what described by Bo et al. (2017). They showed that 6-month intake of DHA (480 mg/die) and EPA (720 mg/die) could improve the perceptual speed, spatial imagery efficiency, and working memory in MCI elderly. Sinn et al. (2012) has also shown that 6-month intake of fish oils (1.55 g of DHA and $0.40 \mathrm{~g}$ of EPA per day) improves cognitive functions and in particular executive efficiency. The same results have not been obtained on patients with known neurodegenerative diseases such as $\mathrm{AD}$, to indicate that greater benefit is drawn from taking PUFA in the early stages of cognitive impairment (Chiu et al., 2008; Cammisuli et al., 2019).

\section{COENZYME Q10}

Coenzyme Q10 (2,3-dimethoxy-5-methyl-6-decaprenyl-1,4benzoquinone) is a fat-soluble compound also known as CoQ10, vitamin Q10, ubidecarenone or ubiquinone. An endogenous substance is produced by mitochondria in doses of about $3-5 \mathrm{mg}$ per day. It is one of the main elements involved in mitochondrial oxidative phosphorylation and acts as an antioxidant. In vitro studies have shown that CoQ10 easily crosses the blood brain barrier (Somayajulu et al., 2005; Sanoobar et al., 2013).

Thanks to its oxidizing and antioxidant properties, it is a cellular redox state modulator. CoQ10 is located in the internal mitochondrial membrane and protects cells from apoptosis at a morphological and at a molecular level (Beal et al., 1994). Furthermore, as a lipophilic antioxidant, it can eliminate radicals from membranes, cytosol and plasma.

It plays an important role in PD. In fact, CoQ10 levels are significantly lower than normal in neuron and platelet mitochondria of PD patients. In vitro studies on fibroblasts of PD patients have shown that CoQ10 intake restores the electron transport chain activity. The first clinical studies on the CoQ10 neuroprotective effects were reported in Beal et al. (1994): this study demonstrated the association between 16-month CoQ10 intake (1,200 mg per day) and a reduced functional decline (44\%) in PD patients. Muller et al. (2003) confirmed these data: 28 PD patients showed moderate symptom improvement thanks to CoQ10 oral administration (360 mg per day).

The antioxidant potential of CoQ10 was further evaluated in a pilot study (Chiu et al., 2008) on 11 patients with Rett Syndrome, a severe neurodevelopmental disorder in which hypoxia-induced oxidative stress associates with the pathogenesis and the disease progression (De Felice et al., 2012; Di Pierro et al., 2020). After 12-month CoQ10 intake (300 mg/day), there was a significant improvement in red blood cells' energy status, suggesting an attenuation of the oxidative stress (De Felice et al., 2012, 2014; Biasini et al., 2018). 
Promising results were also observed in a double-blind randomized clinical trial involving patients with remittingintermittent multiple sclerosis (Sanoobar et al., 2015). The experimental group took $500 \mathrm{mg}$ of CoQ10 for 12 weeks, and showed a significant reduction in inflammatory markers, such as tumor necrosis factor $\alpha$ (TNF- $\alpha$ ), interleukin 6 (IL-6) and matrix metalloproteinase 9 (MMP-9).

Ghasemloo et al. (2021) investigate the effect of CoQ10 and miR-149-5p mimic on miR-149-5p, MMPs and Tyrosine hydroxylase in rat $\mathrm{PD}$ models. This interaction resulted fundamental to understand how to counteract neurodegeneration in PD: the study showed that the combination of the microRNA miR-149 and CoQ10 was able to prevent the oxidative damage in dopaminergic neurons and improve motor function induced by 6-Hydroxypopamine injection by reducing matrix metalloproteinase 2,9 in an animal model.

\section{NIGELLA SATIVA}

Nigella sativa L. (N. sativa), also known as black cumin, is a plant grown in the Mediterranean countries, in the south and south-west Asia, characterized by its high bioactive-compound content seed (e.g., Tocopherols, vitamin A and C, $\beta$-carotene, etc.) and its anti-inflammatory, antioxidant, immunomodulating and anticancer properties (Gholamnezhad et al., 2016; Isik et al., 2017; Ikhsan et al., 2018). N. sativa contains fixed oil (22-38\%), volatile oil $(0.40-1.5 \%)$, proteins $(21-31 \%)$, carbohydrates $(25-$ $40 \%)$, minerals $(3.7-7 \%)$, vitamins $(1-4 \%)$, saponins $(0.013 \%)$ and alkaloids (0.01\%). Its biological activity is associated with its thymoquinone content (TQ) (Bahareh and Hossein, 2016).

Bordoni et al. (2019) revealed the association between the antiinflammatory and antioxidant properties of N. Sativa oil (grown in the Marche region of Italy) and its conservation. Therefore, the Stored Extracted Oil (SEO) and the Fresh Extracted Oil (FEO) were obtained from the same cultivation in order to analyze their thymoquinone content. The cultivated oil showed a higher content of thymoquinone $(7,200 \mathrm{mg} / \mathrm{mL})$ compared to other crops (Mohammed et al., 2016; Aziz et al., 2017) and it was higher in FEO while decreased with storage time.

In murine models, it has been demonstrated that thymoquinone is useful to obtain a delayed onset of the microglia degeneration caused by the oxidative stress (Cobourne-Duval et al., 2016). In addition, TQ is able to improve and regenerate antioxidants enzymes such as glutathione peroxidase and glutathione reductase previously repressed by Beta-amyloid in differentiated cell lines of rats affected by AD (Khan et al., 2012).

The mechanisms by which TQ delays neurodegeneration have been clearly elucidated in Parkinson's disease: it reduces dopaminergic impairment switching on the Nrf2/ARE signaling cascade that triggers the activation of antioxidant genes including Heme Oxygenase 1 (HO-1), Quinone Oxidoreductase (NQO1) and Glutathione-S-Transferase (GST) (Dong et al., 2021).

Moreover, an in vitro study shows that TQ exerts an inhibition on the $\alpha$-synuclein aggregation reducing the inflammatory state and improving antioxidant bioavailability (Ardah et al., 2019).

\section{CHLOROGENIC ACID}

Chlorogenic acid (CA), the main phenolic coffee component, is another polyphenolic substance with an excellent antioxidant activity. It belongs to the chlorogenic acid family (CGA) that are phenolic acids derived from cinnamic acid esterification, such as caffeic, ferulic and p-coumaric acids. The CGA is also widely present in drinks based on herbs, fruits, and vegetables.

Chlorogenic acids have antibacterial, antioxidant and antiinflammatory activities (Liang and Kitts, 2015). Several in vitro and in vivo studies have highlighted their ability to counteract neurodegenerative events. Although a preclinical study on AD transgenic mice reported that caffeine reduces brain beta-amyloid (A $\beta$ ) levels (Arendash et al., 2006, 2009; Cao et al., 2009), it is still unknown which element is specifically related to $\mathrm{AD}$. Currently, few studies have analyzed CGA effects on human cognitive impairment. Epidemiological studies have found that coffee drinking habits reduce cognitive impairment and the risk of developing neurodegenerative diseases such as AD (Panza et al., 2015; Solfrizzi et al., 2015).

In particular, Kim et al. (2019) investigated the association between coffee intake and $\mathrm{AD}$ neuropathological markers in vivo (411 healthy elderly subjects).

The results showed that the coffee intake ( $\geq 2$ cups/day) was associated with lower levels of $\mathrm{A} \beta$ brain deposition compared to its less intake ( $<2$ cups/day), suggesting that a moderate daily coffee intake helps to reduce amyloid pathological deposition in the brain (Kim et al., 2019).

Eskelinen et al. (2009) obtained similar results observing that coffee intake in middle age reduces the risk of developing $\mathrm{AD}$ in the elderly.

Recently, Kato et al. (Socała et al., 2020) conducted a pilot study and described cognitive function changes after 6-months the CGA intake (330 mg/die) in the elderly with subjective memory loss. Significantly higher scores emerged in tests investigating attentional, executive and mnesic functionality. In the same study, there was a significant reduction in $\mathrm{A} \beta 42, \mathrm{~A} \beta 42$ / A $\beta 40$ plasma levels and a significant increase in DHEA-S levels after the CGA intake.

Previous studies have shown that the CGAs improve blood pressure and vascular endothelial functions, both associated with dementia onset (Ota et al., 2010; Kato et al., 2018; Singh et al., 2020): in fact, hypertension, in middle age, is a risk factor for dementia and cognitive impairment in old age and continuous CGA consumption may delay its onset (Ochiai et al., 2004).

Saitou et al. (Watanabe et al., 2006) investigated CGA effects on healthy subjects with subjective memory loss. In this randomized controlled double-blind study, experimental group took a compound based on the CGA caffeoylquinic acids (CQA), feruloylquinic acids (FQA) and dicaffeoylquinic acids (diCQA) for 16 weeks; CQA-FQA total amount was $300 \mathrm{mg}$, obtained by extraction from green coffee beans. Participants underwent a neuropsychological examination (MMSE and RBANS) at baseline, after 8 weeks and after 16 weeks. At the end of the treatment, significant differences between the CGA intake group and the placebo one was evidenced: in particular, elevated scores were recorded in tests investigating motor speed, psychomotor 
speed, and executive functions. The serum concentration of cognitive impairment-linked biomarkers revealed an increase in apolipoprotein A1 (ApoA1) and Transthyretin (TTR) levels in the experimental group at 16 weeks (Watanabe et al., 2006).

Considering these results, the CGA intake may improve not only motor activity, but also the cognitive functions that control its execution and monitor its efficiency.

These results confirm what was described previously by the same authors in a pilot study (Eskelinen et al., 2009).

As far as Parkinson's disease, an in vitro model demonstrated that CGA cell pretreatment reduced 6-hydroxydopamineinduced ROS production and cell apoptosis (Elias et al., 2012). In PD murine models, the CGA improves motor skills, mitochondrial activity, and the expression of antiapoptotic genes like Bcl-2 while reduces the activation of the proapoptotic ones (Saitou et al., 2018).

\section{SELENIUM}

Selenium is an essential micronutrient with a very narrow recommended dietary range. The RDA for selenium is around $55 \mu \mathrm{g} /$ day and it can be integrated with a specific dietary intake. Selenium, in the form of selenocysteine, is a component of 25 selenoprotein classes, including $\mathrm{GPx}$, selenoproteins $\mathrm{P}, \mathrm{W}$ and $\mathrm{R}$ and thioredoxins (TrxR). As an antioxidant, it provides protection from ROS-induced cellular damage (Brauer and Savaskan, 2004; Xiong et al., 2007; Steinbrenner and Sies, 2013).

Its brain concentration changes in Alzheimer's disease patients and Multiple Sclerosis ones; therefore, this element may have an important role in the protection from neurodegeneration (Wenstrup et al., 1990; Ceballos-Picot et al., 1996; Clausen et al., 1998; Cornett et al., 1998). Considering that older people are more exposed to selenium deficiency due to metabolic changes, lower bioavailability, and diet changes (Planas et al., 2004; Arnaud et al., 2007; Letsiou et al., 2009), several studies have hypothesized the possibility of its exogenous assumption in order to prevent aging-related diseases.

Selenoproteins, such as glutathione peroxidases (GPx), play an important role in antioxidant defenses. The main brain selenoproteins are P and GPx: the first one has been identified in senile plaques and neurofibrillary tangles, suggesting its important role against oxidative damage (Bellinger et al., 2008; Takemoto et al., 2010), GPx, which neutralizes peroxides, is expressed by neurons and glial cells (Garcia et al., 2009; Zhang et al., 2010). The biosynthesis of selenoproteins depends on selenium availability. Therefore, an adequate selenium intake may be particularly important for maintaining the elderly function (Steinbrenner and Sies, 2013).

Brazil nut (Bertholletia excelsa) is the richest dietary selenium source, and its intake improves selenium status (Thomson et al., 2008; Cominetti et al., 2012). Although some studies have reported that selenium stet is important for maintaining cognitive efficiency (Berr et al., 2000; Gao et al., 2007; Cardoso et al., 2010), only a few studies have evaluated its real clinical efficacy. Cardoso et al. (2010) analyzed the effects of Brazil nut consumption on cognitive function in a group of older people with MCI. The experimental group took a 5-gram Brazil nut per day, containing approximately $288.75 \mu \mathrm{g}$ of selenium (more than the recommended levels, $55 \mu \mathrm{g} /$ day, but not exceeding the tolerable upper intake level, $400 \mu \mathrm{g} /$ day) (Cardoso et al., 2010). Selenium plasma and erythrocyte concentrations, Gpx activity in erythrocytes, ability to absorb oxygen radicals and MDA, and lipid peroxidation genotoxic product were recorded at baseline and after 6 months. The CERAD neuropsychological battery assessed cognitive functions. After 6 months, no selenium deficiency was observed in the treated group, while control subjects had a level below the cut-off (>84-100 $\mu \mathrm{g} / \mathrm{L}$ ). Furthermore, an increase in plasma and erythrocyte selenium concentrations was observed in the experimental group, there was also a significant improvement in erythrocyte GPX activity. Although no intergroup changes emerged in overall cognitive performance, assessed with the CERAD total score, subtests investigating constructive praxis and verbal fluency showed higher scores in the treated group.

\section{PROBIOTICS}

Probiotics refer to a group of live nonpathogenic microorganisms, which, when administered in adequate amounts, can establish the microbial balance, particularly in the gastrointestinal tract (Wang et al., 2017). Their importance is also related to their antioxidant properties: they act as metal-ion chelators, have their own antioxidant enzymatic systems (SOD and CAT), can produce various metabolites (GSH, butyrate and folate) and mediate Antioxidant Signaling Pathways (Wang et al., 2017).

According to the theory of the "gut-brain axes," the gut microbiota can have significant effects on cognitive alterations and these alterations can be partially reversed by colonization of the gut (Sudo et al., 2004). Bagga et al. (2018) showed that Probiotic administration for 4 weeks was associated with changes in several brain activation pathways regarding emotional memory and emotional decision-making abilities.

Therefore, a rational manipulation of intestinal microbiota through probiotics, could affect positively Central Nervous System-associated disorders. Bonfili et al. (2018) showed that a probiotic formulation (namely SLAB51) counteracted brain oxidative damages associated with $\mathrm{AD}$. A clinical trial by Kobayashi et al. (2017) investigated the effects of oral administration of Bifidobacterium breve strain A1 (B. breve A1) on behavior and physiological processes in $\mathrm{AD}$ model mice. The consumption of $B$. breve A1 suppressed the hippocampal expressions of inflammation and immune-reactive genes that are induced by amyloid- $\beta$ suggesting that $B$. breve A1 has therapeutic potential for preventing cognitive impairment in $\mathrm{AD}$.

Michael et al. (2019) investigated the neuroprotective role of two bacterial consortia, known as Lab4 and Lab4b, using the established SH-SY5Y neuronal cell model. Both consortia were equally able to attenuate intracellular reactive oxygen species accumulation in SH-SY5Y cells.

Another clinical trial showed that heat-killed L. buchneri KU200793 has an important antioxidant activity mediated 


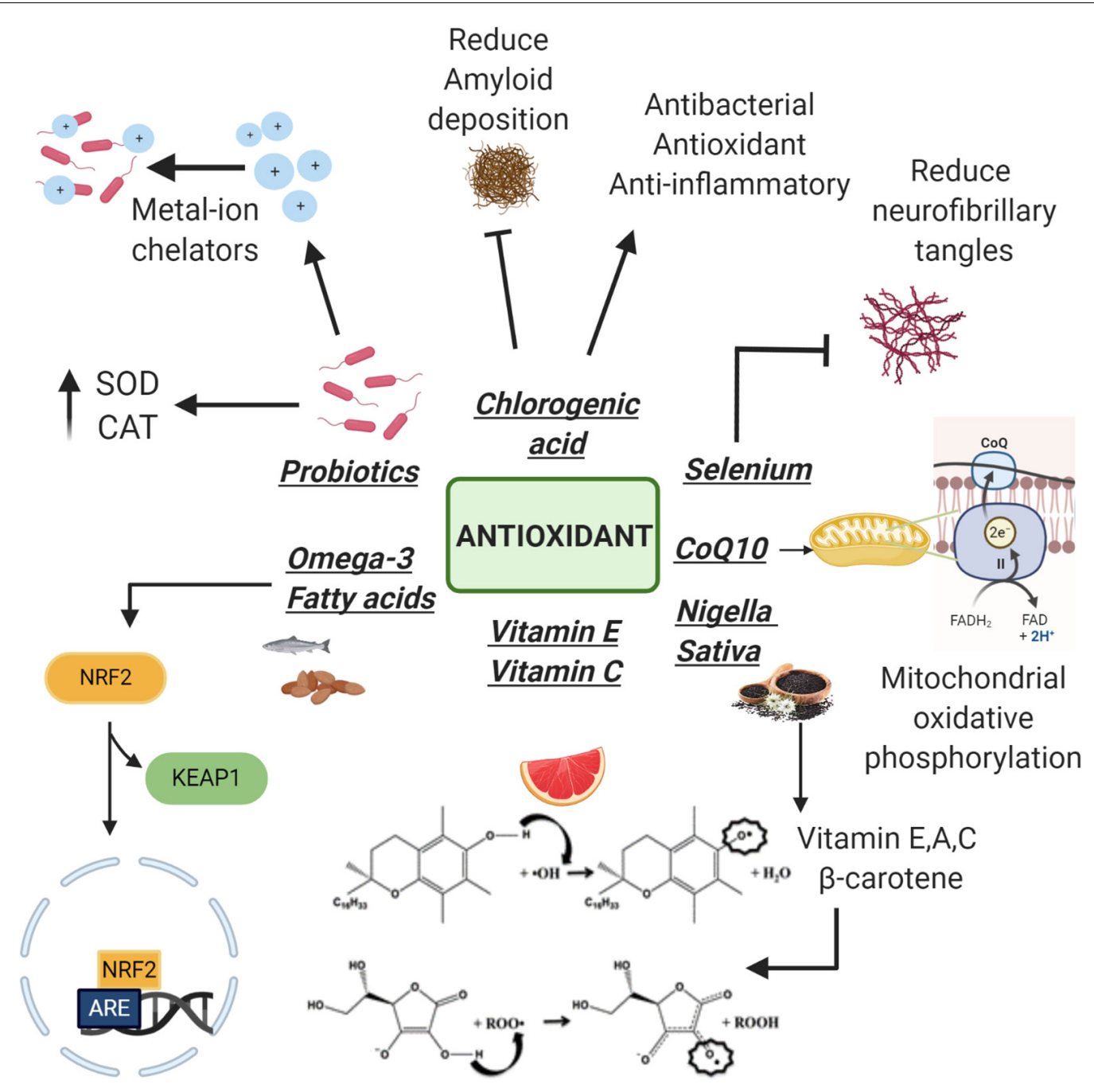

FIGURE 2 | Antioxidants with neuroprotective properties. Following the detachment of Keap1 subunit, Omega-3 increases the antioxidant genes expression. Vitamins E, C, and Nigella sativa (rich in vitamins) neutralize free radicals thanks to the presence of an electrophilic hydroxyl group on the chromane ring. Coenzyme Q10 (CoQ10) plays a fundamental role in the electron transport chain protecting cells from apoptosis at a morphological and molecular level. Selenium is able to reduce neurofibrillary tangle formation while chlorogenic acid reduces amyloid deposition. Probiotics act as metal ion chelators and as antioxidants using their antioxidant enzyme systems: superoxide dismutase and catalase (SOD and CAT).

by its ability to increase levels of BDNF and so its intake can be considered useful in PD prevention (Cheon et al., 2020). Therefore, in accordance with the above, thanks to their antioxidant properties, probiotics seems to be fundamental to delay the progression of these neurodegenerative disorders (Figure 2).

\section{CONCLUSION}

Lots of natural compounds contain antioxidant molecules that are protective against free radical damage affecting brain cells. In vitro and murine models have widely demonstrated that antioxidant improve oxidative stress status of brain cells, cognitive functions and motor skills. Further clinical trials should be conducted in order to understand if these natural compounds, alone or in combination with an appropriate pharmacological treatment, can effectively delay the potential onset of neurodegenerative disorders and ameliorate brain functions. Moreover, it should be better elucidated the actual bioavailability in the central nervous system of these natural antioxidants, and their effective ability to pass the blood brain barrier after an oral intake.

\section{AUTHOR CONTRIBUTIONS}

MA and JF: formal analysis of scientific literature. FF, GS, and SG: writing-original draft preparation. FF and GS: writing-review and editing. CP: supervision. All authors have read and agreed to the published version of the manuscript. 


\section{REFERENCES}

Abramov, A. Y., Berezhnov, A. V., Fedotova, E. I., Zinchenko, V. P., and Dolgacheva, L. P. (2017). Interaction of misfolded proteins and mitochondria in neurodegenerative disorders. Biochem. Soc. Trans. 45, 1025-1033. doi: 10. 1042/bst20170024

Ahmed, N. (2005). Advanced glycation endproducts-role in pathology of diabetic complications. Diabetes Res. Clin. Pract. 67, 3-21. doi: 10.1016/j.diabres.2004. 09.004

Alam, Z. I., Jenner, A., Daniel, S. E., Lees, A. J., Cairns, N., Marsden, C. D., et al. (1997). Oxidative DNA damage in the parkinsonian brain: an apparent selective increase in 8-hydroxyguanine levels in substantia nigra. J. Neurochem. 69, 1196-1203. doi: 10.1046/j.1471-4159.1997.69031196.x

Ardah, M. T., Merghani, M. M., and Haque, M. E. (2019). Thymoquinone prevents neurodegeneration against MPTP in vivo and modulates $\alpha$-synuclein aggregation in vitro. Neurochem. Int. 128, 115-126. doi: 10.1016/j.neuint.2019. 04.014

Arendash, G. W., Mori TCao, C., Mamcarz, M., Runfeldt, M., and Dickson, A. (2009). Caffeine reverses cognitive impairment and decreases brain amyloidbeta levels in aged Alzheimer's disease mice. J. Alzheimer Dis. 17, 661-680. doi: 10.3233/jad-2009-1087

Arendash, G. W., Schleif, W., Rezai-Zadeh, K., Jackson, E. K., Zacharia, L. C., Cracchiolo, J. R., et al. (2006). Caffeine protects Alzheimer's mice against cognitive impairment and reduces brain beta-amyloid production. Neuroscience 142, 941-952. doi: 10.1016/j.neuroscience.2006.07.021

Arnaud, J., Akbaralyc, T. N., Hininger, I., Roussel, A. M., and Berr, C. (2007). Factors associated with longitudinal plasma selenium decline in the elderly: the EVA Study. J. Nutr. Biochem. 18, 482-487. doi: 10.1016/j.jnutbio.2006.09.004

Aziz, S. A., Kurniawati, A., and Faridah, D. N. (2017). Changes of thymoquinone, thymol, and malondialdehyde content of black cumin (Nigella sativa L.) in response to Indonesia tropical altitude variation. HAYATI J. Biosci. 24, 156-161. doi: 10.1016/j.hjb.2017.08.004

Bagga, D., Reichert, J. L., Koschutnig, K., Aigner, C. S., Holzer, P., Koskinen, K., et al. (2018). Probiotics drive gut microbiome triggering emotional brain signatures. Gut Microbes. 209, 486-494. doi: 10.1080/19490976.2018.1460015

Bahareh, A., and Hossein, H. (2016). Black cumin (Nigella sativa) and its active constituent, 647 thymoquinone: an overview on the analgesic and antiinflammatory effects. Planta Med. 82:8. doi: 10.1055/s-0035-1557838

Ballaz, S. J., and Rebec, G. V. (2019). Neurobiology of vitamin C: expanding the focus from antioxidant to endogenous neuromodulator. Pharmacol. Res. 146:1043. doi: 10.1016/j.phrs.2019.104321

Beal, M. F., Henshaw, D. R., Jenkins, B. G., Rosen, B. R., and Schulz, J. B. (1994). Coenzyme Q10 and nicotinamide block striatal lesions produced by the mitochondrial toxin malonate. Ann. Neurol. 36, 882-888.

Beaudart, C., Rolland, Y., Cruz-Jentoft, A. J., Bauer, J. M., Sieber, C., Cooper, C., et al. (2019). Assessment of muscle function and physical performance in daily clinical practice: a position paper endorsed by the european society for clinical and economic aspects of osteoporosis, osteoarthritis and musculoskeletal diseases (ESCEO). Calcif. Tissue Int. 105, 1-14. doi: 10.1007/s00223-01900545-W

Bellinger, F. P., He, Q. P., Bellinger, M. T., Lin, Y., Raman, A. V., White, L. R., et al. (2008). Association of selenoprotein P with Alzheimer's pathology in human cortex. J. Alzheimers Dis. 15, 465-472. doi: 10.3233/jad-2008-15313

Berr, C., Balansard, B., Arnaud, J., Roussel, A. M., and Alpérovitch, A. (2000). Cognitive decline is associated with systemic oxidative stress: the EVA study. etude du Vieillissement Artériel. J. Am. Geriatr. Soc. 48, 1285-1291. doi: 10. 1111/j.1532-5415.2000.tb02603.x

Beyer, R. E. (1994). The role of ascorbate in antioxidant protection of biomembranes: interaction with vitamin $\mathrm{E}$ and coenzyme Q. J. Bioenerget. Biomembr. 26, 349-358. doi: 10.1007/BF00762775

Biasini, B., Marchi, L., Angelino, D., Bedogni, G., Zavaroni, I., Pruneti, C., et al. (2018). Claimed effects, outcome variables and methods of measurement for health claims on foods related to the gastrointestinal tract proposed under regulation (EC) 1924/20Int. J. Food Sci. Nutr. 69, 771-804. doi: 10.1080/ 09637486.2018.1427220

Bo, Y., Zhang, X., Wang, Y., You, J., Cui, H., Zhu, Y., et al. (2017). The n-3 polyunsaturated fatty acids supplementation improved the cognitive function in the Chinese elderly with mild cognitive impairment: A double-blind randomized controlled trial. Nutrients 9:1.

Bonfili, L., Cecarini, V., Cuccioloni, M., Angeletti, M., Berardi, S., Scarpona, S., et al. (2018). SLAB51 probiotic formulation activates sirtl pathway promoting antioxidant and neuroprotective effects in an AD mouse model. Mol. Neurobiol. 55:7987. doi: 10.1007/s12035-018-0973-4

Bordoni, L., Fedeli, D., Nasuti, C., Maggi, F., Papa, F., Wabitsch, M., et al. (2019). Antioxidant and anti-inflammatory properties of nigella sativa oil in human 651 pre-adipocytes. Antioxidants 8:51. doi: 10.3390/antiox8020051

Brauer, A. U., and Savaskan, N. E. (2004). Molecular actions of selenium in the brain: neuroprotective mechanisms of an essential trace element. Rev. Neurosci. 15, 19-32.

Burckhardt, M., Herke, M., Wustmann, T., Watzke, S., Langer, G., and Fink, A. (2016). Omega-3 fatty acids for the treatment of dementia. Cochrane Database Syst. Rev. 4:CD009002.

Calder, P. C. (2002). Dietary modification of inflammation with lipids. Proc. Nutr. Soc. 61, 345-358. doi: 10.1079/pns2002166

Calder, P. C. (2006). n-3 Polyunsaturated fatty acids, inflammation, and inflammatory diseases. Am. J. Clin. Nutr. 83, 1505S-1519S.

Cammisuli, D. M., Cammisuli, S. M., Fusi, J., Franzoni, F., and Pruneti, C. (2019). Parkinson's disease-mild cognitive impairment (PD-MCI): a useful summary of update knowledge. Front. Aging Neurosci. 11:303.

Cao, C., Cirrito, J. R., Lin, X., Wang, L., Verges, D. K., Dickson, A., et al. (2009). Caffeine suppresses amyloid-beta levels in plasma and brain of Alzheimer's disease transgenic mice. J. Alzheimer Dis. 17, 681-697. doi: 10.3233/jad-20091071

Cardoso, B. R., Ong, T., Jacob-Filho, W., Jaluul, O., Freitas, M. I., and Cozzolino, S. M. (2010). Nutritional status of selenium in Alzheimer's disease patients. Br. J. Nutr. 103, 803-806.

Ceballos-Picot, I., Merad-Boudia, M., Nicole, A., Thevenin, M., Hellier, G., Legrain, S., et al. (1996). Peripheral antioxidant enzyme activities and selenium in elderly subjects and in dementia of Alzheimer's type-place of the extracellular glutathione peroxidase. Free Rad. Biol. Med. 20, 579-587. doi: 10.1016/08915849(95)02058-6

Cenini, G., Lloret, A., and Cascella, R. (2019). Oxidative stress in neurodegenerative diseases: from a mitochondrial point of view. Oxid Med. Cell Longev. 9:2105607.

Cheon, M. J., Lim, S. M., Lee, N. K., and Paik, H. D. (2020). Probiotic properties and neuroprotective effects of lactobacillus buchneri ku200793 isolated from korean fermented foods. Int. J. Mol. Sci. 21:12. doi: 10.3390/ijms21041227

Chiu, C. C., Su, K. P., Cheng, T. C., Liu, H. C., Chang, C. J., Dewey, M. E., et al. (2008). The effects of omega-3 fatty acids monotherapy in Alzheimer's disease and mild cognitive impairment: a preliminary randomized double-blind placebo-controlled study. Prog. Neuro Psychopharmacol. Biol. Psychiatry 32, 1538-1544. doi: 10.1016/j.pnpbp.2008.05.015

Clausen, J., Jensen, G. E., and Nielsen, S. A. (1998). Selenium in chronic neurologic diseases. multiple sclerosis and Batten's disease. Biol. Trace Element Res. 15, 179-203. doi: 10.1007/978-1-4612-4606-0_14

Cobley, J. N., Fiorello, M. L., and Bailey, D. M. (2018). 13 reasons why the brain is susceptible to oxidative stress. Redox Biol. 15, 490-503. doi: 10.1016/j.redox. 2018.01.008

Cobourne-Duval, M. K., Taka, E., Mendonca, P., Bauer, D., and Soliman, K. F. (2016). The antioxidant effects of thymoquinone in activated bv-2 murine microglial cells. Neurochem. Res. 664, 3227-3238. doi: 10.1007/s11064-0162047-1

Cominetti, C., de Bortoli, M. C., Garrido, A. B. Jr., and Cozzolino, S. M. (2012). Brazilian nut consumption improves selenium status and glutathione peroxidase activity and reduces atherogenic risk in obese women. Nutr. Res. 32, 403-407. doi: 10.1016/j.nutres.2012.05.005

Cooke, M. S., Evans, M. D., Dizdaroglu, M., and Lunec, J. (2003). Oxidative DNA damage: mechanisms,mutation, and disease. FASEB J. 17, 1195-1214. doi: 10.1096/fj.02-0752rev

Cornett, C. R., Markesbery, W. R., and Ehmann, W. D. (1998). Imbalances of trace elements related to oxidative damage in Alzheimer's disease brain. Neurotoxicology 19, 339-345.

Cruz-Jentoft, A. J., Bahat, G., Bauer, J., Boirie, Y., Bruyère, O., Cederholm, T., et al. (2019). Sarcopenia: revised european consensus on definition and diagnosis. Age Ageing 48, 16-31. doi: 10.1093/ageing/afy169 
De Felice, C., Della Ragione, F., Signorini, C., Leoncini, S., Pecorelli, A., Ciccoli, L., et al. (2014). Oxidative brain damage in Mecp2-mutant murine models of Rett syndrome. Neurobiol. Dis. 68, 66-77. doi: 10.1016/j.nbd.2014.04.006

De Felice, C., Signorini, C., Leoncini, S., Pecorelli, A., Durand, T., Valacchi, G., et al. (2012). The role of oxidative stress in Rett syndrome: an overview. Ann. N.Y. Acad. Sci. 1259, 121-135. doi: 10.1111/j.1749-6632.2012.06611.x

Di Pierro, D., Ciaccio, C., Sbardella, D., Tundo, G. R., Bernardini, R., Curatolo, P., et al. (2020). Effects of oral administration of common antioxidant supplements on the energy metabolism of red blood cells. Attenuation of oxidative stressinduced changes in Rett syndrome erythrocytes by CoQ. Mol. Cell. Biochem. 463, 101-113. doi: 10.1007/s11010-019-03633-5

Dong, J., Zhang, X., Wang, S., Xu, C., Gao, M., Liu, S., et al. (2021). Thymoquinone prevents dopaminergic neurodegeneration by attenuating oxidative stress via the Nrf2/ARE pathway. Front. Pharmacol. 4:615598.

Dukan, S., Farewell, A., Ballesteros, M., Taddei, F., Radman, M., and Nystrom, T. (2000). Protein oxidation in response to increased transcriptional or translational errors. Proc. Natl. Acad. Sci. U.S.A. 97, 5746-5749. doi: 10.1073/ pnas. 100422497

Dupont, J., Dedeyne, L., Dalle, S., Koppo, K., and Gielen, E. (2019). The role of omega-3 in the prevention and treatment of sarcopenia. Aging Clin. Exp. Res. 31, 825-836. doi: 10.1007/s40520-019-01146-1

Dyall, S. C. (2015). Long-chain omega-3 fatty acids and the brain: a review of the independent and shared effects of EPA, DPA and DHA. Front. Aging Neurosci. 7:1-15.

Elias, M. F., Goodell, A. L., and Dore, G. A. (2012). Hypertension and cognitive functioning: a perspective in historical context. Hypertension 60, 260-268. doi: 10.1161/hypertensionaha.111.186429

Eskelinen, M. H., Ngandu, T., Tuomilehto, J., Soininen, H., and Kivipelto, M. (2009). Midlife coffee and tea drinking and the risk of late-life dementia: a population-based CAIDE study. J. Alzheimers Dis. 16, 85-91. doi: 10.3233/jad2009-0920

Fotuhi, M., Mohassel, P., and Yaffe, K. (2009). Fish consumption, long-chain omega-3 fatty acids and risk of cognitive decline or Alzheimer disease: a complex association. Nat. Clin. Pract. Neurol. 557 5, 140-152. doi: 10.1038/ ncpneuro1044

Fukuzawa, K., and Gebicki, J. M. (1983). Oxidation of $\alpha$-tocopherol in micelles and liposomes by the hydroxyl, perhydroxyl, and superoxide free radicals. Arch. Biochem. Biophys. 226, 242-251. doi: 10.1016/0003-9861(83)90290-4

Gabbita, S. P., Lovell, M. A., and Markesbery, W. R. (1998). Increased nuclear DNA oxidation in the brain in Alzheimer's disease. J. Neurochem. 71, 2034-2040. doi: 10.1046/j.1471-4159.1998.71052034.x

Gao, S., Jin, Y., Hall, K. S., Liang, C., Unverzagt, F. W., Ji, R., et al. (2007). Selenium level and cognitive function in rural elderly Chinese. Am. J. Epidemiol. 165, 955-965. doi: 10.1093/aje/kwk073

Garcia, T., Esparza, J. L., Nogues, M. R., Romeu, M., Domingo, J. L., and Gómez, M. (2009). Oxidative stress status and RNA expression in hippocampus of an animal model of Alzheimer's disease after chronic exposure to aluminum. Hippocampus 20, 218-225.

Getoff, N. (2013). Vitamin C: electron emission, free radicals, and biological activity. In Vivo 27, 565-570. doi: 10.1016/j.lfs.2008.12.006

Ghasemloo, E., Mostafavi, H., Hosseini, M., Forouzandeh, M., Eskandari, M., and Mousavi, S. S. (2021). Neuroprotective effects of coenzyme Q10 in Parkinson's model via a novel Q10/miR-149-5p/MMPs pathway. Metab. Brain Dis. 36, 2089-2100.

Gholamnezhad, Z., Havakhah, S., and Boskabady, M. H. (2016). Preclinical and clinical effects of Nigella sativa and its constituent, thymoquinone: a review. J. Ethnopharmacol. 190, 372-386. doi: 10.1016/j.jep.2016.06.061

Good, P. F., Hsu, A., Werner, P., Perl, D. P., and Olanow, C. W. (1998). Protein nitration in Parkinson's disease. J. Neuropathol. Exp. Neurol. 57, 338-342.

Gudelsky, G. A. (1996). Effect of ascorbate and cysteine on the 3,4methylenedioxymethamphetamine-induced depletion of brain serotonin. J. Neural Transm. (Vienna) 103, 1397-1404. doi: 10.1007/BF01271253

Halliwell, B., and Gutteridge, J. M. C. (1984). Oxygen toxicity, oxygen radicals, transition metals and disease. Biochem. J. 219, 1-14. doi: 10.1042/bj2190001

Harman, D. (1956). Aging: a theory based on free radical and radiation chemistry. J. Gerontol. 11, 298-300.

Harrison, F. E., Dawes, S. M., Meredith, M. E., Babaev, V. R., Li, L., and May, J. M. (2010a). Low vitamin C and increased oxidative stress and cell death in mice that lack the sodium dependent vitamin C transporter SVCT2. Free Radic. Biol. Med. 49, 821-829.

Harrison, F. E., Meredith, M. E., Dawes, S. M., Saskowski, J. L., and May, J. M. (2010b). Low ascorbic acid and increased oxidative stress in gulo(-/-) mice during development. Brain Res. 1349, 143-152. doi: 10.1016/j.brainres.2010.06. 037

Hawkins, R. A., Sangster, K., and Arends, M. J. (1998). Apoptotic death of pancreatic cancer cells induced by polyunsaturated fatty acids varies with double bond number and involves an oxidative mechanism. J. Pathol. 185, 61-70. doi: 10.1002/(sici)1096-9896(199805)185:1<61::aid-path49>3.0.co;2-8

Ikeda, K., Tienda, A. A., Harrison, F. E., and Kawakami, K. (2021). Decreased content of ascorbic acid (vitamin C) in the brain of knockout mouse models of $\mathrm{Na}+, \mathrm{K}+-\mathrm{ATPase}-\mathrm{related}$ neurologic disorders. PLoS One 16:e0246678. doi: 10.1371/journal.pone.0246678

Ikhsan, M., Hiedayati, N., Maeyama, K., and Nurwidya, F. (2018). Nigella sativa as an anti-inflammatory agent in asthma. BMC Res. Notes 11:744.

Isik, S., Kartal, M., and Aslan Erdem, S. (2017). Quantitative analysis of thymoquinone in Nigella Sativa L. (Black Cumin) seeds and commercial seed oils and seed oil capsules from Turkey. J. Fac. Pharm. Ankara/Ankara ECZ Fac. Derg. 41, 34-41. doi: 10.1501/eczfak_0000000593

Ito, S., Mori, T., Kanazawa, H., and Sawaguchi, T. (2007). Differential effects of the ascorbyl and tocopheryl derivative on the methamphetamine-induced toxic. Behavior Toxicity Toxicol. 240, 96-110. doi: 10.1016/j.tox.2007.07.022

Jiang, Q. (2014). Natural forms of vitamin E: metabolism, antioxidant, and antiinflammatory activities and their role in disease prevention and therapy. Free Radic Biol Med. 72, 76. doi: 10.1016/j.freeradbiomed.2014.03.035

Jiao, J., Li, Q., Chu, J., Zeng, W., Yang, M., and Zhu, S. (2014). Effect of n-3 PUFA supplementation on cognitive function throughout the life span from infancy to old age: a systematic review and meta-analysis of randomized controlled trials. Am. J. Clin. Nutr. 100, 1422-1436. doi: 10.3945/ajcn.114.095315

Johri, A., and Beal, M. F. (2012). Antioxidants in Huntington's disease. Biochim. Biophys. Acta 1822, 664-674.

Kato, M., Ochiai, R., Kozuma, K., Sato, H., and Katsuragi, Y. (2018). Effect of chlorogenic acid intake on cognitive function in the elderly: a pilot study. Evid. Based Complement. Altern. Med. 2018:8608497.

Khan, A., Vaibhav, K., Javed, H., Khan, M. M., Tabassum, R., Ahmed, M. E., et al. (2012). Attenuation of $A \beta$-induced neurotoxicity by thymoquinone via inhibition of mitochondrial dysfunction and oxidative stress. Mol. Cell. Biochem. 369, 55-65. doi: 10.1007/s11010-012-1368-x

Khan, F., Garg, V. K., Singh, A. K., and Kumar, T. (2018). Role of free radicals and certain antioxidants in the management of Huntington's disease: a review. J. Anal. Pharm. Res. 7, 386-392.

Khanna, S., Roy, S., Ryu, H., Bahadduri, P., Swaan, P. W., Ratan, R. R., et al. (2003). Molecular basis of vitamin E action: tocotrienol modulates 12-lipoxygenase, a key mediator of glutamate-induced neurodegeneration. J. Biol. Chem. 278, 43508-43515.

Kim, J. W., Byun, M. S., Yi, D., Lee, J. H., Jeon, S. Y., Jung, G., et al. (2019). Coffee intake and decreased amyloid pathology in human brain. Transl. Psychiatry 9:270.

Kishida, K. T., and Klann, E. (2007). Sources and targets of reactive oxygen species in synaptic plasticity and memory. Antioxidants Redox Sign. 9, 233-244. doi: 10.1089/ars.2007.9.233

Kobayashi, Y., Sugahara, H., Shimada, K., Mitsuyama, E., Kuhara, T., Yasuoka, A., et al. (2017). Therapeutic potential of Bifidobacterium breve strain A1 for preventing cognitive impairment in Alzheimer's disease. Sci. Rep. 7:135. doi: 10.1038/s41598-017-13368-2

Kontush, K., and Shekatolina, S. (2004). Vitamin E in neurodegenerative disorders: Alzheimer's disease. Ann. N.Y. Acad. Sci. 1031:249. doi: 10.1196/annals.1331. 025

Kumar, A., and Ratana, R. R. (2016). oxidative stress and huntington's disease: the good, the bad, and the ugly. J. Huntingt. Dis. 5, 217-237. doi: 10.3233/jhd160205

Lee, K. H., Kim, U. J., Cha, M., and Lee, B. H. (2021). Chronic treatment of ascorbic acid leads to age-dependent neuroprotection against oxidative injury in hippocampal slice Cultures. Int. J. Mol. Sci. 22:1608. doi: 10.3390/ ijms 22041608

Letsiou, S., Nomikos, T., Panagiotakos, D., Pergantis, S. A., Fragopoulou, E., Antonopoulou, S., et al. (2009). Serum total selenium status in Greek adults and 
its relation to age. the ATTICA study cohort. Biol. Trace Elem. Res 128, 8-17. doi: 10.1007/s12011-008-8252-2

Liang, N., and Kitts, D. D. (2015). Role of chlorogenic acids in controlling oxidative and inflammatory stress conditions. Nutrients 8:16. doi: 10.3390/nu8010016

Lundberg, J. O., Weitzberg, E., and Gladwin, M. T. (2008). The nitrate-nitritenitric oxide pathway in physiology and therapeutics. Nat. Rev. Drug Discov. 7, 156167. doi: $10.1038 / \mathrm{nrd} 2466$

Lushchak, V. I. (2014). Free radicals, reactive oxygen species, oxidative stress and its classification. Chem. Biol. Interact. 224, 164-175. doi: 10.1016/j.cbi.2014.10.016

Machado, F. R., Ferreira, A. G., da Cunha, A. A., Tagliari, B., Mussulini, B. H., Wofchuk, S., et al. (2011). Homocysteine alters glutamate uptake and $\mathrm{Na}+\mathrm{K}+-$ ATPase activity and oxidative status in rats hippocampus: protection by vitamin C. Metab. Brain Dis. 26, 61-67. doi: 10.1007/s11011-011-9232-3

Michael, D. R., Davies, T. S., Loxley, K. E., Allen, M. D., Good, M. A., Hughes, T. R., et al. (2019). In vitro neuroprotective activities of two distinct probiotic consortia. Benef. Microbes. 10:437. doi: 10.3920/BM2018.0105

Migliore, L., and Coppedè, F. (2009). Environmental-induced oxidative stress in neurodegenerative disorders and aging. Mutation Res. 674, 73-84. doi: 10.1016/ j.mrgentox.2008.09.013

Miller, E., Markiewicz, L., Kabziński, J., Odrobina, D., and Majsterek, I. (2017). Potential of redox therapies in neurodegenerative disorders. Front. Biosci. Elite 9:214-234. doi: 10.2741/e797

Mohammed, N. K., Abd Manap, M. Y., Tan, C. P., Muhialdin, B. J., Alhelli, A. M., and Meor Hussin, A. S. (2016). The effects of different extraction methods on antioxidant properties, chemical composition, and thermal behavior of black seed (Nigella sativa L.) oil. Evid. Based Complement. Alternat. Med. 2016:6273817.

Moncada, S., and Higgs, A. (1993). The L-arginine-nitric oxide pathway. N. Engl. J. Med. 329, 2002-2020.

Muller, T., Buttner, T., Gholipour, A. F., and Kuhn, W. (2003). Coenzyme Q10 supplementation provides mild symptomatic benefit in patients with Parkinson's disease. Neurosci. Lett. 341, 201-204. doi: 10.1016/s0304-3940(03) 00185-x

Nuzzo, D., Baldassano, S., Amato, A., Picone, P., Galizzi, G., Caldara, G. F., et al. (2019). Glucagon-like peptide- 2 reduces the obesity-associated inflammation in the brain. Neurobiol. Dis. 121, 296-304.

Ochiai, R., Jokura, H., and Suzukietal, A. (2004). Green coffee bean extract improves human vasoreactivity. Hypertension Res. 27, 731-737. doi: 10.1291/ hypres. 27.731

Osakada, F., Hashino, A., Kume, T., Katsuki, H., Kaneko, S., and Akaike, A. (2004). Alpha-tocotrienol provides the most potent neuroprotection among vitamin E analogs on cultured striatal neurons. Neuropharmacology 47, 904-915. doi: 10.1016/j.neuropharm.2004.06.029

Ota, N., Soga, S., Murase, T., Shimotoyodome, A., and Hase, T. (2010). Consumption of coffee 705 polyphenols increases fat utilization in humans. J. Health Sci. 56, 745-751. doi: 10.1248/jhs.56.745

Panza, F., Solfrizzi, V., Barulli, M. R., Bonfiglio, C., Guerra, V., Osella, A., et al. (2015). Coffee, tea, and caffeine consumption and prevention of late-life cognitive decline and dementia: a systematic review. J. Nutr. Health Aging 19, 313-313. doi: 10.1007/s12603-014-0563-8

Parletta, N., Milte, C. M., and Meyer, B. J. (2013). Nutritional modulation of cognitive function and mental health. J. Nutr. Biochem. 24, 725-743. doi: 10.1016/j.jnutbio.2013.01.002

Planas, M., Conde, M., Audivert, S., Pérez-Portabella, C., Burgos, R., Chacón, P., et al. (2004). Micronutrient supplementation in mild Alzheimer disease patients. Clin. Nutr. 23, 265-272. doi: 10.1016/s0261-5614(03)00106-7

Rahman, K. (2007). Studies on free radicals, antioxidants, and co-factors. Clin. Interv. Aging 2, 219-236.

Reed, T. T. (2011). Lipid peroxidation and neurodegenerative disease. Free Radical. Biol. Med. 51, 1302-1319. doi: 10.1016/j.freeradbiomed.2011.06.027

Rodriguez-Rocha, H., Garcia-Garcia, A., Pickett, C., Li, S., Jones, J., Chen, H., et al. (2013). Compartmentalized oxidative stress in dopaminergic cell death induced by pesticides and complex I inhibitors: distinct roles of superoxide anion and superoxide dismutases. Free Radical. Biol. Med. 416, 370-383. doi: 10.1016/j.freeradbiomed.2013.04.021

Saitou, K., Ochiai, R., Kozuma, K., Sato, H., Koikeda, T., Osaki, N., et al. (2018). Effect of chlorogenic acids on cognitive function: a randomized, double-blind, placebo-controlled trial. Nutrients 10:1337. doi: 10.3390/nu10101337
Sanoobar, M., Eghtesadi, S., Azimi, A., Khalili, M., Jazayeri, S., and Reza Gohari, M. (2013). Coenzyme Q10 supplementation reduces oxidative stress and increases antioxidant enzyme activity in patients with relapsing-remitting multiple sclerosis. Int. J. Neurosci. 123, 776-782. doi: 10.3109/00207454.2013.801844

Sanoobar, M., Eghtesadi, S., Azimi, A., Khalili, M., Khodadadi, B., Jazayeri, S., et al. (2015). Coenzyme Q10 supplementation ameliorates inflammatory markers in patients with multiple sclerosis: a double blind, placebo, controlled randomized clinical trial. Nutrit. Neurosci. 18, 169-176. doi: 10.1179/1476830513y. 0000000106

Schirinzi, T., Martella, G., Imbriani, P., Di Lazzaro, G., Franco, D., Colona, V. L., et al. (2019). Dietary vitamin e as a protective factor for parkinson's disease: clinical and experimental evidence. Front. Neurol. 10:1. doi: 10.3389/fneur.2019. 001eCollection 2019

Shen, L., and Ji, H. F. (2012). Vitamin E: supplement versus diet in neurodegenerative diseases. Trends Mol. Med. 18, 443-445. doi: 10.1016/j. molmed.2012.04.010

Sies, H. (2015). Oxidative stress: a concept in redox biology and medicine. Redox Biol. 4, 180-183.

Simonetto, M., Infante, M., Sacco, R. L., Rundek, T., and Della-Morte, D. A. (2019). Novel anti inflammatory role of omega-3 pufas in prevention and treatment of atherosclerosis and vascular cognitive impairment and dementia. Nutrients 11:2279. doi: 10.3390/nu11102279

Singh, S. S., Rai, S. N., Birla, H., Zahra, W., Rathore, A. S., Dilnashin, H. et al. (2020). Neuroprotective effect of chlorogenic acid on mitochondrial dysfunction-mediated apoptotic death of da neurons in a parkinsonian mouse model. Oxid Med. Cell Longev. 2020:6571484.

Sinn, N., Milte, C. M., Street, S. J., Buckley, J. D., Coates, A. M., Petkov, J., et al. (2012). Effects of n-3 fatty acids, EPA v. DHA, on depressive symptoms, quality of life, memory and executive function in older adults with mild cognitive impairment: a 6-month randomised controlled trial. Br. J. Nutr. 107, 1682-1693. doi: 10.1017/s0007114511004788

Smythies, J. R. (1996). The role of ascorbate in brain: therapeutic implications. J. R. Soc. Med. 89:241. doi: 10.1177/014107689608900501

Socała, K., Szopa, A., Serefko, A., Poleszak, E., and Wlaź, P. (2020). Neuroprotective effects of coffee bioactive compounds: a review. Int. J. Mol. Sci. 22:107. doi: $10.3390 /$ ijms 22010107

Sokoła-Wysoczańska, E., Wysoczański, T., Wagner, J., Czyż, K., Bodkowski, R., Lochyński, S., et al. (2018). Polyunsaturated fatty acids and their potential therapeutic role in cardiovascular system disordersa review. Nutrients 10, 1-21.

Solfrizzi, V., Panza, F., Imbimbo, B. P., D’Introno, A., Galluzzo, L., Gandin, C., et al. (2015). Italian longitudinal study on aging working group. coffee consumption habits and the risk of mild cognitive impairment: the italian longitudinal study on aging. J. Alzheimers Dis. 47, 889-899. doi: 10.3233/jad-150333

Somayajulu, M., McCarthy, S., Hung, M., Sikorska, M., Borowy-Borowski, H., and Pandey, S. (2005). Role of mitochondria in neuronal cell death induced by oxidative stress, neuroprotection by Coenzyme Q. Neurobiol. Dis. 18, 618-627. doi: 10.1016/j.nbd.2004.10.021

Stansley, B. J., and Yamamoto, B. K. (2014). Chronic L-dopa decreases serotonin neurons in a subregion of the dorsal raphe nucleus. J. Pharmacol. Exp. Ther. 351, 440-447. doi: 10.1124/jpet.114.218966

Stavrinou, P. S., Andreou, E., Aphamis, G., Pantzaris, M., Ioannou, M., Patrikios, I. S., et al. (2020). The effects of a 6-month high dose omega-3 and omega6 polyunsaturated fatty acids and antioxidant vitamins supplementation on cognitive function and functional capacity in older adults with mild cognitive impairment. Nutrients 12:325. doi: 10.3390/nu12020325

Steele, M. (2007). The molecular basis of the prevention of Alzheimer's disease through healthy nutrition. Exp. Gerontol. 42, 28-36. doi: 10.1016/j.exger.2006. 06.002

Steinbrenner, H., and Sies, H. (2013). Selenium homeostasis and antioxidant selenoproteins in brain: implications for disorders in the central nervous system. Arch. Biochem. Biophys. 536, 152-157. doi: 10.1016/j.abb.2013.02.021

Steinert, J. R., Chernova, T., and Forsythe, I. D. (2010). Nitric oxide signaling in brain function, dysfunction, and dementia. Neuroscientist 16:435. doi: 10.1177/ 1073858410366481

Sudo, N., Chida, Y., Aiba, Y., Sonoda, J., Oyama, N., Yu, X. N., et al. (2004). Postnatal microbial colonization programs the hypothalamic-pituitary-adrenal system for stress response in mice. J. Physiol. 558, 263-275. doi: 10.1113/ jphysiol.2004.063388 
Taghizadeh, M., Tamtaji, O. R., Dadgostar, E., Daneshvar Kakhaki, R., Bahmani, F., Abolhassani, J., et al. (2017). The effects of omega-3 fatty acids and vitamin E cosupplementation on clinical and metabolic status in patients with Parkinson's disease: a randomized, double-blind, placebo-controlled trial. Neurochem. Int. 108, 183-189. doi: 10.1016/j.neuint.2017.03.014

Takemoto, A. S., Berry, M. J., and Bellinger, F. P. (2010). Role of selenoprotein P in Alzheimer's disease. Ethn. Dis. 20(Suppl. 1), 92-95.

Tan, B. L., Norhaizan, M. E., and Liew, W. P. (2018). Nutrients and oxidative stress: friend or foe? Oxid. Med. Cell. Longev. 2018:9719584.

Tewari, D., Sah, A. N., Bawari, S., Nabavi, S. F., Dehpour, A. R., Shirooie, S., et al. (2021). Role of nitric oxide in neurodegeneration: function, regulation, and inhibition. Curr. Neuropharmacol. 19:114. doi: 10.2174/ 1570159x18666200429001549

Thomson, C. D., Chisholm, A., McLachlan, S. K., and Campbell, J. M. (2008). Brazil nuts: an effective way to improve selenium status. Am. J. Clin. Nutr. 87, 379-384. doi: 10.1093/ajcn/87.2.379

Tian, H., Ye, X., Hou, X., Yang, X., Yang, J., and Wu, C. (2016). SVCT2, a potential therapeutic target,protects against oxidative stress during ethanolinduced neurotoxicity via JNK/p38 MAPKs, NF- $\kappa B$ and miRNA125a-5p. FREE Radic. Biol. Med. 96, 362-373. doi: 10.1016/j.freeradbiomed.2016.03.039

Tse, J. K. Y. (2017). Gut Microbiota, Nitric oxide, and microglia as prerequisites for neurodegenerative disorders. ACS Chem. Neurosci. 8, 1438-1444. doi: 10.1021/ acschemneuro.7b00176

Ulatowski, L. M., and Manor, D. (2015). Vitamin E and neurodegeneration. Neurobiol. Dis. 537, 78-83. doi: 10.1016/j.nbd.2015.04.002

Valko, M., Leibfritz, D., Moncol, J., Cronin, M. T., Mazur, M., and Telser, J. (2007). Free radicals andantioxidants in normal physiological functions and human disease. Int. J. Biochem. Cell Biol. 39, 44-44. doi: 10.1016/j.biocel.2006.07.001

Wang, Y., Wu, Y., Wang, Y., Xu, H., Mei, X., Yu, D., et al. (2017). Antioxidant properties of probiotic bacteria. Nutrients 9:5. doi: 10.3390/nu9050521

Wang, Z., Ma, C., Meng, C. J., Zhu, G. Q., Sun, X. B., Huo, L., et al. (2012). Melatonin activates the Nrf2-ARE pathway when it protects against early brain injury in a subarachnoid hemorrhage model. J. Pineal Res. 53:129. doi: 10.1111/ j.1600-079x.2012.00978.x

Watanabe, T., Arai, Y., and Mitsuietal, Y. (2006). The blood pressure-lowering effect and safety of chlorogenic acid from green coffee bean extract in essential hypertension. Clin. Exp. Hypert. 28, 439-449. doi: 10.1080/10641960600798655
Wenstrup, D., Ehmann, W. D., and Markesbery, W. R. (1990). Trace element imbalances in isolated subcellular fractions of Alzheimer's disease brains. Brain Res. 533, 125-131. doi: 10.1016/0006-8993(90)91804-p

Xiong, S., Markesbery, W. R., Shao, C., and Lovell, M. A. (2007). SelenoL-methionine protects against beta-amyloid and iron/hydrogen peroxidemediated neuron death. Antiox. Redox Sign. 9, 457-467. doi: 10.1089/ars.2006. 1363

Youdim, K. A., Martin, A., and Joseph, J. A. (2000). Essential fatty acids and the brain: possible health implications. Int. J. Dev. Neurosci. 18, 383-399. doi: 10.1016/s0736-5748(00)00013-7

Yurko-Mauro, K., Alexander, D. D., and Van Elswyk, M. E. (2015). Docosahexaenoic acid and adult memory: a systematic review and meta-analysis. PLoS One 10:1-18.

Zhang, S., Rocourt, C., and Cheng, W. (2010). Selenoproteins and the aging brain. Mech. Ageing Dev. 131, 253-260. doi: 10.1016/j.mad.2010.02.006

Zhang, Y., Chen, J., Qiu, J., Li, Y., Wang, J., and Jiao, J. (2016). Intakes of fish and polyunsaturated fatty acids and mild-to-severe cognitive impairment risks: a dose-response meta-analysis of 21 cohort studies. Am. J. Clin. Nutr. 103, 330-340. doi: 10.3945/ajcn.115.124081

Conflict of Interest: The authors declare that the research was conducted in the absence of any commercial or financial relationships that could be construed as a potential conflict of interest.

Publisher's Note: All claims expressed in this article are solely those of the authors and do not necessarily represent those of their affiliated organizations, or those of the publisher, the editors and the reviewers. Any product that may be evaluated in this article, or claim that may be made by its manufacturer, is not guaranteed or endorsed by the publisher.

Copyright (c) 2021 Franzoni, Scarfò, Guidotti, Fusi, Asomov and Pruneti. This is an open-access article distributed under the terms of the Creative Commons Attribution License (CC BY). The use, distribution or reproduction in other forums is permitted, provided the original author(s) and the copyright owner(s) are credited and that the original publication in this journal is cited, in accordance with accepted academic practice. No use, distribution or reproduction is permitted which does not comply with these terms. 